\title{
ACERCA DEL ORIGEN Y DE LA CRONOLOGÍA DE LOS CRISTALES DE ROCA LLAMADOS FATIMÍES: EL VIDRIO DE BADAJOZ Y LA BOTELLA DE ASTORGA
}

\author{
ROSARIO GARCÍA GIMÉNEZ \\ FERNANDO VALDÉs FERNÁNDEZ
}

\section{Resumen}

Después de realizar análisis de laboratorio sobre un fragmento de vidrio descubierto en la Alcazaba de Badajoz y de compararlo con otros ejemplos procedentes de Fusțāt, se demuestra la procedencia egipcia de aquél. Además, su comparación con los análisis que también se llevaron a cabo sobre una botella "fatimí", conservada en el Museo de la Catedral de Astorga, ha permitido precisar que ésta está realizada en cristal de roca y que es un prototipo del fragmento aparecido en Badajoz. Todo ello añade un dato más para reconocer, con el apoyo de argumentos arqueológicos, a El Cairo como seguro origen de la mayor parte de los cristales de roca llamados "fatimíes" llegados hasta nosotros, que sólo habían sido atribuidos a esa ciudad con ayuda de referencias literarias.

\section{Summary}

Having carried out a laboratory analysis on a glass fragment discovered in the Alcazaba of Badajoz, and through comparisons with other examples from Fusțāt, its Egyptian origin has been proved. Moreover, its comparison with the analysis that was also carried out on a "fatimí" bottle kept in the Museum of the Cathedral of Astorga, has allowed us to state, accurately, that this bottle was made from rock crystal, and that it is a prototype of the fragment which appeared in Badajoz. This, supported by archaeological reasoning, adds further weight to recognise Cairo as the undisputed origin of the so-called "fatimí" rock crystals, which, up until now, had been attributed to this city only by virtue of literary references.

Una investigación arqueológica raramente puede darse por concluida si quedan cabos sueltos por aclarar. Este trabajo se refiere a uno de ellos, pendiente de resolución desde la primera campaña de excavación en la Alcazaba de Badajoz, hace ahora veintiún años. El catálogo de piezas egipcias de cristal de roca conservadas en España, que estoy realizando 
en colaboración con mi maestro y amigo M. Casamar ${ }^{1}$, me ha permitido recapitular y poner en relación el primero de los objetos del enunciado con la magnífica botella fatimí conservada en el Museo de la Catedral de Astorga. El resto de la investigación se debe a la eficaz colaboración de la Dra. Rosario García Giménez, coautora de este artículo.

\section{EL VIDRIO DE BADAJOZ (Lám. 1, fig. 1)}

Lo excavamos durante el verano de $1977^{2}$. Desde un primer momento le supusimos procedencia egipcia, aunque manteniendo, al principio, ciertas reservas, más por prudencia que por convencimiento de la capacidad de los talleres andalusíes para producir piezas semejantes (VALDÉs, F., 1985, p. 353). Los paralelos ornamentales con otras de cristal de roca, precisamente las que otorgan un mayor valor documental a este menudísimo objeto, y de vidrio son del todo obvias. Sobre la primera de las materias citadas se constatan decoraciones vegetales parecidas sobre tres piezas conocidas. Una es la propia botella de Astorga. Otra está depositada en la catedral de Halberstadt (Alemania) (LAMm, CJ., 1929/30, I, p. 197; II, lám. 67:12) y la tercera es el famoso relicario llamado del "Sanguine Miraculoso", custodiado en el tesoro de la basílica de San Marcos de Venecia (Ibidem, I, p. 160; II, lám. 59:7). Otro ejemplar, con marcadas diferencias estilísticas fue recuperado en Madīnāt al-Zahrāo(Córdoba) ${ }^{3}$. De vidrio tallado se nos han preservado total o parcialmente numerosos ejemplos: una botellita, procedente con bastante seguridad de Fustāạt ${ }^{4}$, varias piezas más pertenecen al Museo Benaki de Atenas 5 y otras muchas, conservadas en diferentes colecciones (Oliver, P., 1961; PinderWilson, R. and SCANLON, G.T., 1987 y KRÖGER, J., E.P.).

Durante la Guerra de la Independencia, concretamente durante el definitivo asedio inglés de 1812, dirigido por Lord Wellington, se situó en las inmediaciones del actual Hospital Militar, dentro de la Alcazaba de Badajoz, una batería de artillería atendida por soldados españoles y polacos, al servicio del imperio francés. Algunos de ellos murieron durante el asalto británico, que en aquel lugar alcanzó una especial virulencia. Las bajas hubieron de producirse durante los últimos momentos del asedio, a juzgar por las circunstancias en que aparecieron los esqueletos de los soldados muertos. Se les retiró el armamento y, aprovechando

\footnotetext{
${ }^{1}$ Gracias al generoso patrocinio de la Fundación Max van Berchem de Ginebra. Nuestro agradecimiento a don Bernardo Velado Graña, canónigo conservador del Museo de la Catedral de Astorga, por la amable deferencia con que atendió nuestras peticiones.

${ }^{2}$ Es un fragmento de galbo (AL77/1/46/22) de muy cortas dimensiones, con una pared de extraordinaria finura $(0.5 \mathrm{~mm}$., en la zona de menor grosor, y $1.5 \mathrm{~mm}$., en el relieve). Formó parte de una botella esférica de cuello largo. Es transparente. Lleva decoración vegetal de roleos, retallada y una moldura de sección triangular, también tallada, de aristas muy agudas. Se halla depositado actualmente en el Museo Arqueológico de Badajoz. Cf. VALDÉs, F. (1985), pp. 360-361, fig. 158:1.

${ }^{3}$ LAMm, que lo incluyó dentro del grupo de los cristales tallados, lo consideró fabricado en Egipto y lo fechó en el siglo X. Cf. Velázqlez Bosco, R. (1912), pp. 81 y 83, figs. 46 y 48, lám. 55; Gómez-Morexo, M. (1919), p. 375; Laмn, C.J. (1929/30), I, p. 166; II, lám. 61:14.

+ Es de color verde claro y está adornada de un modo muy parecido, aunque las hojas de las palmetas no están digitada. Cf. LAMM, C.J. (1929/30), I, p. 160; II, lám. 59:7.

5 No tienen lugar de procedencia y se sitúan temporalmente entre los últimos años del siglo IX y el X. Cf. Cl.airmoıt, CH.W. (1977), p. 95, n² 317, lám. XIX; pp. 98-99, n² 324, 325, 326, 335, 336 y 337, láms. XIX y XXII.
} 


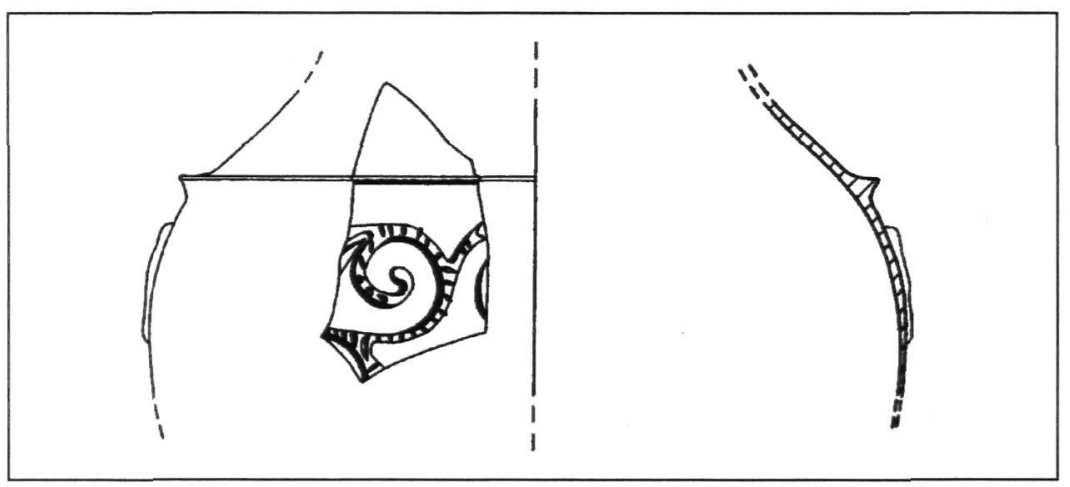

Figura 1. Reconstrucción de la botella a la que perteneció el vidrio excavado en la Alcazaba de Badajoz. (Dibujo J. Fernández)

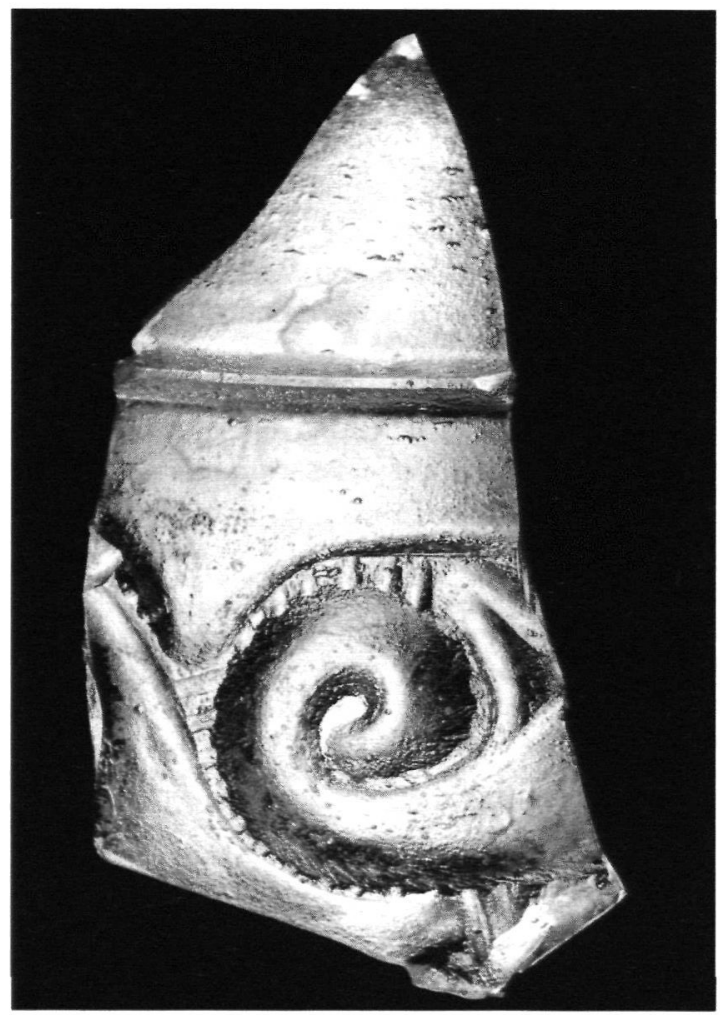

Lámina 1. Fragmento de vidrio excavado en la Alcazaba de Badajoz (Foto J. Patterson) 
una zanja excavada allí mismo se les cubrió de tierra sin más ceremonias ${ }^{6}$. Conquistada la plaza y cambiados los contingentes de tropas que la guarnecían, se perdió la el recuerdo de la fosa común.

Algún tiempo después, sobre el nivel donde yacían los cadáveres se abrió una canalización procedente del área del Hospital Militar que debía desaguar poco más adelante. Sus autores ignoraban que debajo había una tumba colectiva. Es, por lo tanto, indudable que nuestro objeto procedía de remociones de terreno en el área más elevada del recinto, la que hubo de ocupar la zona residencial del conjunto desde sus orígenes y, con independencia de la fecha que se le atribuya, procede de niveles removidos de origen islámico, los mismos que, en ese sondeo concreto, habían sido rotos por las zanjas militares de comienzos del siglo XIX.

\section{LA BOTELLA DE ASTORGA? (Lámina 2, figura 2)}

Se la conoce popularmente como Cáliz de Santo Toribio o Jarra de Nuestra Señora. Forma parte de un cáliz barroco, de plata dorada ${ }^{8}$. Tiene dos asas del mismo metal y estilo ${ }^{9}$

El cuerpo de la pieza lo forma una botella, de cuerpo globular y cuello cilíndrico, que hubo de ser largo, sujeta por tornillos a la montura. Las paredes son delgadas. En realidad el cáliz debió ejecutarse con fines más ornamentales que prácticos, porque la apariencia esconde, dada la estrechez del cuello de la botella, una evidente dificultad de uso.

Los autores que se han referido a este extraordinario objeto han dudado acerca de su naturaleza vítrea o cristalina. Mientras que F. Rodríguez Díaz (1909, p. 550) y R. SchmidT (1912, pp. 65-66) lo consideraron cristal de roca - el segundo sin haberlo visto directamente. M. Gómez-Moreno, quien primero lo estudió sistemáticamente, mantuvo una opinión fluctuante y acabó por decantarse hacia el vidrio tallado ${ }^{10}$. Sólo la realización de análisis de labo-

${ }^{6}$ Prueba de la premura con que fueron inhumados es la aparición, en la faltriquera de uno de los cadáveres, de una moneda de oro, acuñada en el reinado de Carlos III. Si hubiese habido tiempo los cadaveres habrian sido registrados. Cf. VAldés, F. (1978); González, P. y Canto, A. (1978) y Alcazaba (1979), n². 27.

7 Joyas (1892), lám. 14, Rodríguez Díez, (1909), p. 550; SCHмidt, R. (1912), pp. 65-66; Gómez-Moreno, M. (1919), p. 376, fig. 207, lám. CXXXV; Gómez-MoreNo, M. (1925/26), pp. 161-162; Exposición Internacional (1929), p. 60; Lamm, C.J. (1930), p. 197, lám. 67:11; Camón AzNar, J. (1936/39), p. 403; ERdMaix, K. (1951), p. 146; GómeZMoreio, M. (1951), pp. 341-344, fig. 403b, Gómez-Moreno, M. (1961), pp. 650 y 751; Velado Graĩa, B. (1991), pp. 193-196, lám. 244; Velado Graĩa, B. (1993), p. 234, n² 154.

${ }^{8}$ Se conserva en el relicario de la Catedral de Astorga, dentro de una montura de plata dorada -unos 575 gramos de peso-, fechada por M. Gómez-Moreno (1919, p. 376, lám. 135) en el siglo XVIII (1925/26, pp. 161-62 y 1929, p. 60).

$\begin{array}{ll}9 \text { Lugar de depósito: } & \text { Astorga (León). Museo de la Catedral } \\ \text { Altura del cáliz: } & 251 \mathrm{~mm} . \\ \text { Altura del vidrio: } & 104 \mathrm{~mm} . \\ \text { Diámetro del gollete: } & 30 \mathrm{~mm} . \\ \text { Diámetro máximo: } & 92 \mathrm{~mm} . \\ \text { Diámetro del solero: } & 48 \mathrm{~mm} . \\ \text { Peso: } & 218 \mathrm{gr} .\end{array}$




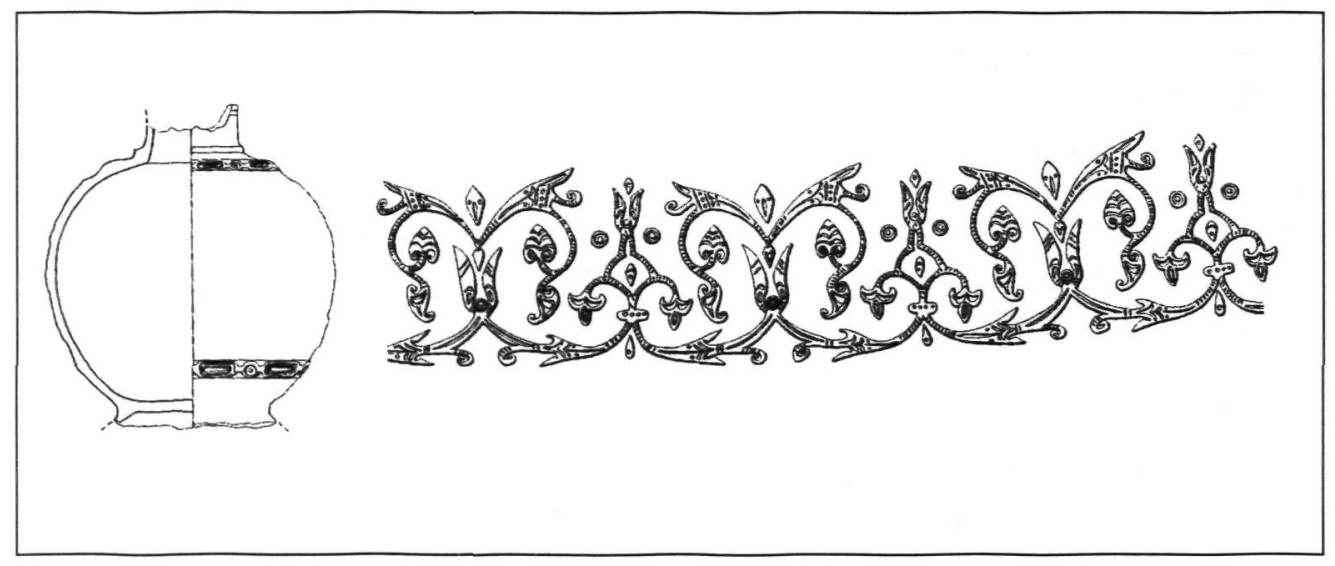

Figura 1. Reconstrucción de la botella a la que perteneció el vidrio excavado en la Alcazaba de Badajoz. (Dibujo J. Fernández)

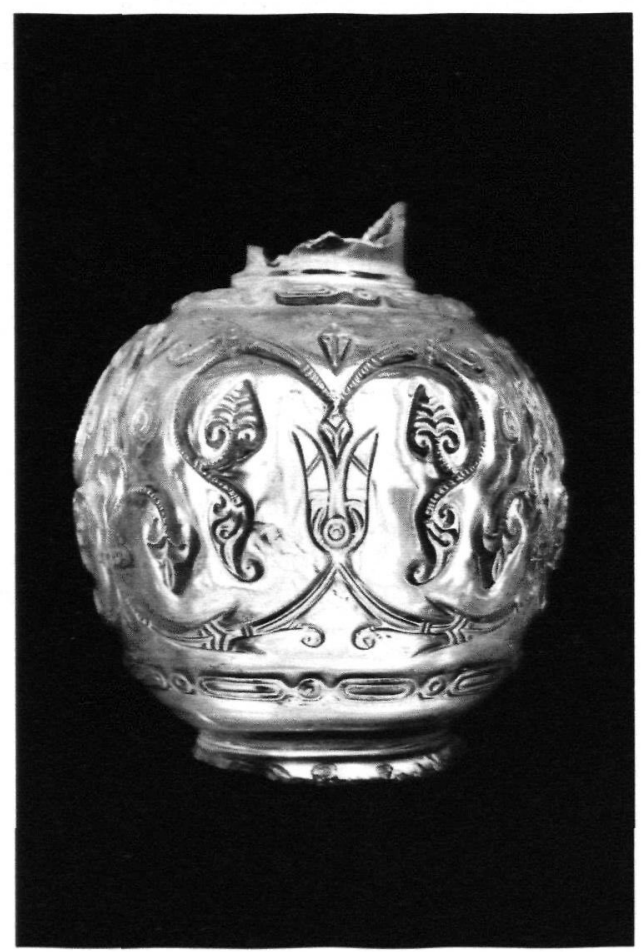

Lámina 2. Botella de cristal de roca conservada en el Museo de la Catedral de Astorga. Sin el armazón de plata dorada. (Foto J. Patterson) 
ratorio y los propios llevados a cabo in situ, con ayuda del microscopio, podían dar una solución indudable al problema. Tiene anillo de solero exvasado, con numerosas huellas de golpes. En ningún punto conserva su parte inferior completa.

Nuestra botella lleva decoración tallada en relieve. Es muy estilizada, con motivos arborescentes a base de ramajes que brotan de ejes simétricos. Todos los elementos vegetales son muy carnosos y abundan las palmetas trifoliadas, las palmas segmentadas, con los dos extremos inferiores enrollados sobre sí mismos, y las medias palmetas. Dos grecas con ovas y perlas forman sendos cordones continuos a lo largo de sus extremos superior e inferior.

Figuró por primera vez en el Catálogo de la Exposición Histórico-Europea de Madrid, de 1892 (Joyas 1892, lám. 14), aunque ya había sido someramente descrita por Fray Jacobo de Castro ${ }^{11}$, quien relata la tradición piadosa que le atribuía la virtud de haber servido como jarra de agua a la Virgen y conservar siempre algunas gotas en su interior. Más comúnmente se la llama Cáliz de Santo Toribio ${ }^{12}$.

Su forma no es corriente en las de su serie, aunque, como señaló M. Gómez-Moreno, desde una perspectiva algo sesgada "...esta forma de redoma no es conocida por ejemplares de allá [de Oriente], mientras que aquí en España era la usual" (Gómez-MORENo, M. (1919), p. 376), basada en su frecuente aparición en escenas cortesanas representadas sobre marfili13. En realidad, su rareza estriba más en el material del soporte que en la morfología del objeto, puesto que el tipo de botella con largo gollete y cuerpo esférico, más o menos piriforme, es el más habitual entre los fabricados en vidrio soplado y aparece ampliamente documentado y difundido.

El único paralelo morfológico en cristal de roca es la botella conservada en la catedral de Halberstadt (Alemania) ${ }^{14}$.

${ }^{10}$ En la primera obra donde lo analizó (1919, p. 376) lo consideró "vidrio transparente", opinión que parece haber mantenido, con una calculadora ambigüedad de lenguaje, en trabajos posteriores (1925/26, pp. 161-162, 1951, III, pp. 341-344), hasta decantarse, por clasificarlo como "vidrio tallado" (1961, pp. 650 y 751). En su último trabajo (1961, p. 751) dice que es "...vidrio transparente, como cristal". Las opiniones de C.J. LAMm (1930, p. 197, lám. 67:11) y K. ERdmaxx (1951, p. 146) parecen ser subsidiarias, a juzgar por su aparato crítico, de la de M. Gómez-Morexo, de 1919, y aún más, la de J. CAMÓx AZxar (1936/39, p. 403).

Años después ha vuelto sobre el asunto B. Velado Grax̃a, Director del Museo de la Catedral de Astorga, quien, desde su conocimiento directo de la pieza, incide en tener su materia prima por cristal (1991, pp. 193-196, lám. 244; 1993, p. 234, $\mathrm{n}^{\mathrm{Q}}$ 154). Nosotros mismos dudamos y, en los primeros momentos, consideramos, después de un minucioso estudio directo, que se trataba de vidrio transparente soplado y tallado.

${ }^{11}$ Citado por F. RodríGlez Díez (1909), p. 550.

${ }_{12}$ Como bien afirma M. Gómez-Moreno: "...ni es cáliz ni a este santo del siglo V es posible referirlo" (1919, p. 376); "...ni Morales ni Flórez hacen memoria de ello; pero enfrente de estas negaciones ningün dato fidedigno puedo allegar tocante a su origen" (1925/26, p. 162).

13 Objetos muy semejantes aparecen en las representaciones de corte de los marfiles cordobeses. Cf. KC̈HNEL, E. (1971), pp. 38-39, lám. XVIII:31c -bote de al-Mugira, Museo del Louvre, París, fechado en el 968-, pp. 39-40, lám. XIX - Bote del Museo Victoria and Albert, Londres, fechado en el 970-, pp. 41-43, láms. XXIII y XXVI:35h -arqueta del Museo de Navarra, Pamplona, fechada en 1005-, pp. 44-45, lám. XVIIa -caja del Museo Victoria and Albert, Londres, fechada genéricamente en el siglo XI.

${ }^{1+}$ LAMm, J.C. (1929/30), I, p. 197 y II, lám. 67:12. Fue traída esta pieza a la catedral en 1205 por Konrad von Krosigk, obispo de la ciudad, a su vuelta de la cuarta cruzada. Está colocada en una montura de filigrana, en plata dorada, de obra alemana fechable entre los siglos XIII y XIV. 
Nuestra pieza acusa bastante semejanza de detalles ornamentales y un apreciable parecido compositivo con la conservada en la iglesia de Santa Fé de Conques (Aveyron, Francia) ${ }^{15}$

Todos los autores que han estudiado la pieza de Astorga coinciden en atribuirle una cronología que, en el caso de M. Gómez-Moreno, oscila de modo general entre los siglos X y XI ${ }^{16}$ y, a juicio de C.J. Lamm, se fija a principios del XI (LAmm, C.J., 1929/30, I, p. 197), opinión esta compartida y matizada por K. Erdmann, quien lo incluyó dentro del grupo "d" de su clasificación, esto es, en una fase fatimí temprana, 969-ca. 1000 de nuestra era (Idem). De ninguna manera puede compartirse la teoría de J. Camón Aznar, quien sitúa el momento de fabricación en el siglo IX (1936/39, p. 40).

El único objeto con el que parece poseer una gran semejanza decorativa es con el desaparecido cáliz de Saint-Denis ${ }^{17}$.

La composición ornamental que la cubría, aceptando que la pintura de la Biblioteca Nacional de París no permite mayores alegrías interpretativas, guarda una estrechísima semejanza con nuestra botella. En los dos casos los motivos, soporte de una especie de cáliz floral central, se desarrollan a modo de largos brazos curvilíneos, por la parte inferior, y dan lugar, en paralelo con otra línea contrapeada de ramajes que parece brotar de la misma flor central y se desarrolla por la parte alta, a una forma envolvente. El eje de cada una de estas composiciones lo constituye el propio brote floral central. Uno y otro objetos hubieron de tener un origen común y, desde luego, una fecha igual.

${ }^{15}$ Se trata, en este caso, de un fragmento de borde cilindrico perteneciente a una vasija de apreciables dimensiones -unos $10 \mathrm{~cm}$ de alto. Se hallaba dentro del arca de las reliquias de Santa Fé-siglo XII-, cuando ésta fue abierta en 1875 (GAYlLaRD, G. y otros, 1963, pp. 144-145, lám. 65). El único motivo decorativo que se conserva completo se dispone a los lados de un eje central, con los extremos finalizados en hojas trifoliadas y el centro ensanchado en forma de rombo y con un botón segmentado y cuarteado en el centro. Esta composición resulta menos conseguida que la de Astorga, cuyas formas decorativas son más redondeadas y carnosas y tienen unos perfiles menos geométricos y rígidos. Aún así, sus fechas no pueden ser muy lejanas, ni sus lugares de procedencia ni talleres de ejecución tampoco. El ejemplar francés, a juzgar por las propias fechas de la caja donde estaba depositado, no puede exceder los primeros años del siglo XII (Ibidem, pp. 130-131 y 145). Encaja bien con lo fatimí egipcio del siglo XI, quizás en su primera mitad. Cf. LAMM, C.J. (1929/30), I, p. 200, lám. 68:6 y GAYLARD, G. y otros (1963), p. 144.

${ }^{16}$ Gómez-Morexo, M. (1919), p. 376; (1925/26), pp. 161-162; (1929), p. 60. Implícitamente afirma esta cronología en (1951), III, pp. 341-344, fig. 403b.

17 De este cáliz, que formó parte del tesoro de la famosa abadía parisina, sólo queda una magnífica reproducción a la acuarela, obra de Peiresc, en la Biblioteca Nacional de París; su rastro se perdió en 1798 (CoxwaY, M., 1915. P. 144; Montesqliol-Fezensac, B. et Gaborit-Chopin, D., 1977, pp. 51-52, lám. 34a). La parte superior la formaba una pieza globular de cristal de roca, adornada con motivos vegetales en relieve. Da la sensación de que, según aparece reproducida en la acuarela, fuese originalmente una botella muy parecida a la de Astorga, rota o recortada o ambas cosas a la vez, para adaptarla a su nuevo uso, pero, como en el caso de la española, más por estética que por utilidad. A juzgar por la posición de los motivos ornamentales, debía estar colocada invertida. 


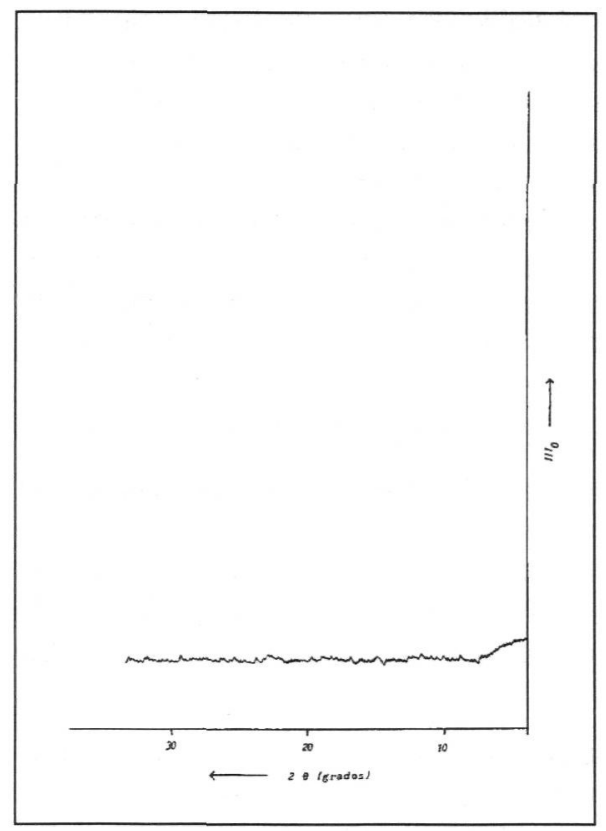

Figura 3. Vidrio transparente, excavado en la Alcazaba de Badajoz

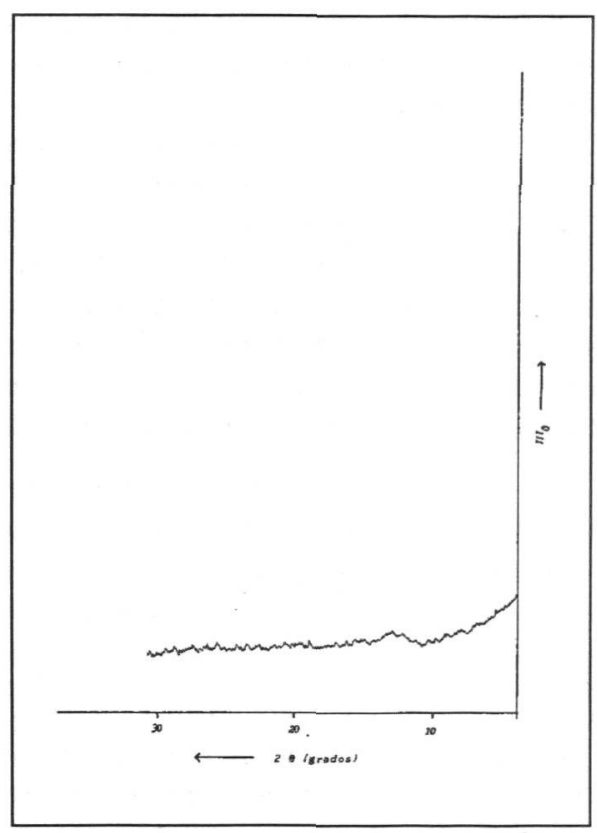

Figura 4. Vidrio tricolor, procedente de Fusțāṭ.

\section{ANÁLISIS QUíMICO}

El estudio estilístico del vidrio de Badajoz nos llevó a atribuirle, como ya hemos dicho, procedencia egipcia, habida cuenta de la calidad de su manufactura y de la falta de antecedentes andalusíes de esta categoría técnica suficientemente conocidos y documentados por vía arqueológica.

Sólo los análisis químicos podían aportar, sin embargo, una evidencia concluyente al respecto, por comparación con otras piezas de seguro origen egipcio. Las tres que sirvieron de parangón proceden de Fustạt y pertenecen a la colección de M. Casamar, a quien expresamos nuestro agradecimiento ${ }^{18}$.

La botella del museo catedralicio de Astorga planteaba, por su parte, interrogantes importantes, como ya vimos, en cuanto a la naturaleza de su materia. Los autores que se

${ }^{18}$ M2: Vidrio transparente, tallado, con decoraciones animales en melado y verde; M3: Vidrio transparente, a molde, con motivos epigráficos en melado; M4: Vidrio transparente, a molde, con motivos geométricos. 
habían referido a ella dudaban, oscilando entre considerarla vidrio o cristal de roca. En el primer examen que hicimos de la pieza, con ocasión de su dibujo y fotografiado, nos decidimos por aceptar la primera de las propuestas porque, si bien carecía de las pequeñas burbujas características del vidrio, se observaban indicios, como una cierta aureola en torno a una de las cenefas decorativas, que se nos antojaba marca del molde con cuya ayuda se habría fabricado. No desperdiciamos, sin embargo, la posibilidad de llevar a cabo análisis de laboratorio más profundos, para confirmar o rechazar lo que, en principio, era sólo una observación superficial. Habida cuenta de la excelente conservación del objeto era difícil tomar muestras. Tuvimos la buena fortuna de encontrar en el fondo una pequeñísima esquirla saltada del borde en algún momento y conservada casualmente en el interior. Valiéndonos de esta muestra, que presentaba un alto grado de confianza, pudimos realizar los análisis pertinentes.

En el supuesto inicial, al considerar vidrio la materia del objeto, empleamos como elemento comparativo cuatro muestras vítreas. Tres de ellas (M1, M2 y M3) procedían de Fusțāt y la cuarta era el fragmento de vidrio tallado, exhumado durante las excavaciones dirigidas por uno de nosotros en la Alcazaba de Badajoz durante el mes de julio de 1977 (VALDÉs, F. (1985), pp. 360-316, figura 158:2). El último de los ejemplos estudiados fue el mínimo fragmento recogido en el fondo de nuestra botella.

Así pues, los análisis perseguían un triple propósito: confirmar definitivamente la naturaleza de la botella de Astorga, conocer los componentes del vidrio aparecido en Badajoz y, por comparación con los reconocidos en las otras muestras de seguro origen egipcio, establecer sin dudas su lugar de procedencia, en la medida en que puede hacerse con seguridad gracias a la enorme cantidad porcentual de sodio contenido por las piezas vítreas fabricadas en el país del Nilo. Sobre todas estas muestras se llevaron a cabo tres tipos de análisis:

\section{Observación con lupa binocular y microscopio óptico}

En todas las muestras se detectaron numerosas burbujas esféricas, negras con el centro claro, típicas de los vidrios, alineadas, y, en algunos casos, núcleos de óxidos de hierro, de color marrón y pequeñas dimensiones. Excepciones son la muestra de Badajoz, en la que no se observan burbujas, y la de Astorga, muy limpia, con inclusiones bifásicas detectables y con una fractura escalonada típica. El peso específico de ésta dio un valor de 2.65.

\section{Difracción de Rayos $\mathrm{X}$}

Se llevó a cabo sobre las muestras en difractograma de polvo, con difractómetro PHILIPS PW-1035, trabajando con cátodo de cobre y filtro de níquel a una velocidad de barrido de $2^{\circ}$ por minuto, entre cuatro y treinta y dos grados, los resultados figuran en los diagramas correspondientes.

La interpretación del difractograma induce a pensar que todas las muestras son de vidrio, excepto la de Astorga, que, una vez estudiada, permitió la identificación de dos picos de difracción, $4.26 \AA$ y $3.33 \AA$, que se corresponden con los del cuarzo o, lo que es lo mismo en nuestro caso, al cristal de roca. 


\section{Análisis químico por vía búmeda}

Atacando la muestra en un reactor de teflón con ácido fluorhídrico y acomplejando la muestra con ácido bórico, para evitar el desprendimiento de tretrafluoruro de silicio.

\section{Espectrometría de absorción atómica (AAS)}

Medición de elementos químicos mayoritarios $\left(\mathrm{SiO}_{2}, \mathrm{Al}_{2} \mathrm{O}_{3}, \mathrm{Fe}_{2} \mathrm{O}_{3}, \mathrm{CaO}, \mathrm{MgO}, \mathrm{K} 2 \mathrm{O}\right.$, $\mathrm{Na}_{2} \mathrm{O}, \mathrm{TiO}_{2}, \mathrm{MnO}$ y $\mathrm{PbO}$ ) y minoritarios (níquel, cobre, zinc, cromo y cobalto).

\section{IMPORTANCIA CIENTÍFICA DE LA PIEZA DE VIDRIO}

A pesar de que casi todos los autores coinciden en atribuir a la mayoría de los alrededor de 180 cristales de roca islámicos tallados con decoración vegetal, que convencionalmente conocemos como fatimíes, un origen egipcio (CASAMAR, M. y VALDÉs, F., 1996), lo cierto es que sigue habiendo todavía grandes dudas al respecto, debidas sobre todo a su descontextualización. Muchas se hallan depositadas en museos y otras, desde muy antiguo, en monasterios, iglesias y catedrales. Las de estos lugares suelen estar empleadas, si son frascos, como relicarios y, si son piezas de ajedrez, como adorno de objetos religiosos.

Prácticamente ninguna de estas raras obras se exhumó en el transcurso de una excavación arqueológica y, cuando fue así, siempre fuera de niveles cronológicamente concordes a los de la época en que presumiblemente se tallaron ${ }^{19}$.

Los análisis exhaustivos realizados por ciertos autores para intentar atribuirles una cronología han sido exclusivamente estilísticos y, por lo tanto, muy sujetos no sólo al subjetivismo del investigador de turno, sino a variables tan contingentes como la capacidad económica del destinatario -dentro siempre de una escala social alta-, la maestría del o de los autores, la calidad general del taller y, por qué no, la evolución formal de los motivos ornamentales, de los que, además, no se han publicado tablas tipológicas.

\footnotetext{
${ }^{19}$ Algunos fragmentos de cristal de roca se recuperaron en el transcurso de una excavación arqueológica bien documentada en la Zeyrek Camii de Estambul, antigua iglesia de Cristo Pantocrator. Para nuestra desgracia no aportan evidencia apreciable que haga variar en nada las fechas de comienzo de la producción "egipcia". Esa iglesia fue fundada por la emperatriz Irene ( $† 1134$ ), esposa del emperador Juan II ( $† 1143$ ), entre 1108 y 1124, luego los cristales no pudieron llegar allí antes del lapso comprendido entre ambas fechas. En opinión de sus excavadores, que basan su afirmación en la comparación con el riquísimo lote de vidrios recuperado en el mismo depósito, unos y otros deben fecharse en torno a 1126 (MeGaw, A.H.S., 1963, P. 346). Parece que los cristales de roca pertenecen a la etapa de máxima producción de los talleres fatimíes, según la clasificación de K. ERDMA.x (1951, pp. 144-145).

La teoría del propio Megaw respecto a su parecido con algunos de los objetos guardados en el tesoro de San Marcos de Venecia, lo que haria pensar en una pertenencia de todos a la misma iglesia de Cristo Pantocrator, antes del saqueo de Constantinopla de 1204 , con ser atractiva, no ayuda a nuestro propósito clasificatorio. Sólo testimonia a favor de un origen común, en cuanto a la fecha de manufactura, pero nada impide, sin excluir esa teoría, que llegaran a la capital del Imperio Romano de Oriente después de finalizada la producción de los talleres cairotas y antes de 1204, estuvieran o no guardadas en idéntico lugar.
} 


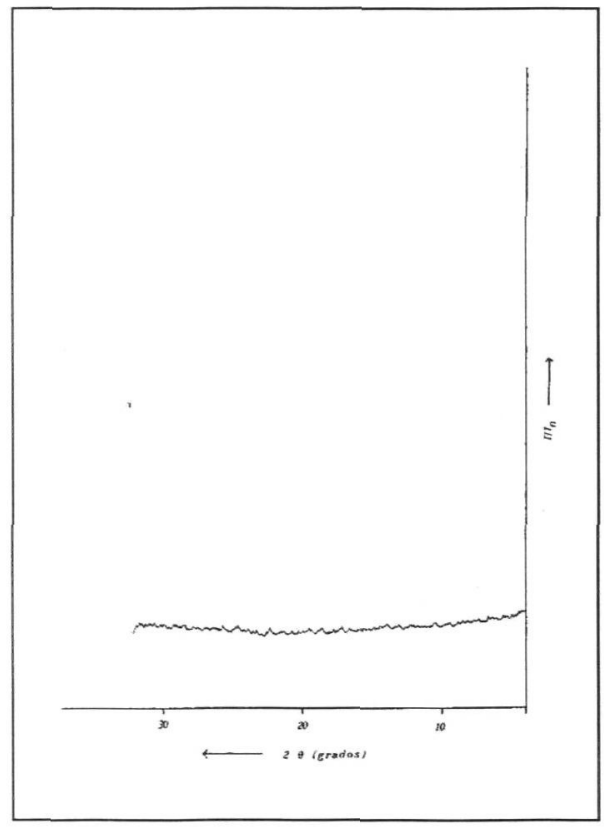

Figura 5. Vidrio transparente, procedente de Fustạt.

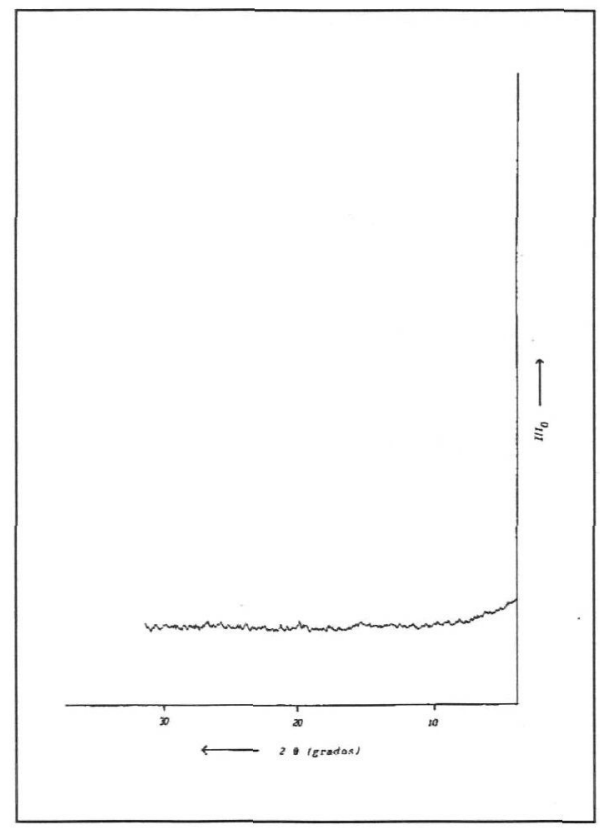

Figura 6. Vidrio transparente, procedente de Fustạt.

De todas las obras conservadas sólo tres están fechadas, por inscripciones, en términos absolutos. Dos son jarras: una, conservada en el tesoro de San Marcos de Venecia (LAmm, C.J., 1930, lám. 67:1; Erdmann, K., 1971, pp. 101-119) y, la otra, en el Museo degli Argenti de Florencia (Heikamp, D., 1980, $\mathrm{n}^{\circ} 23$, pp. 240-241, figs. 42-43) ${ }^{20}$. La tercera de las piezas es un creciente del Germanisches Nationalmuseum de Nuremberga, con el nombre grabado del califa al-Zāhir (1021-1036), perteneciente a la misma dinastía (ERDMANN, K., 1951, p. 143). Fuera de estos pocos ejemplos, carecemos de datos arqueológicos de indudable certeza, sólo de algunos textos, para atribuir a Egipto la cuna de tan exóticas manufacturas.

La más antigua referencia a un cristal de roca hecha por un árabe es la descripción de una lámpara que estuvo colgada en el miḅrāb de la mezquita mayor de Damasco. Fue un regalo de al-Walīd I (705-715). Desconocemos su origen y nada ayuda a probar la existencia de talleres en la Siria omeya donde se trabajase el cristal de roca (SHalem, A., 1994). Sólo

${ }^{20}$ Aquélla lleva inscrito el nombre del califa fatimí al-cAzìz (975-996) y ésta un letrero cúfico, leído por D.S. Rice (1956), en el que se dice: "Especialmente, para el general de los generales". Se ha identificado a este personaje con Husayn ibn Yawhar, conquistador de Egipto para los fatimíes. Recibió el título de qā̄id al-quwwād (=general de generales o generalísimo) el 5 de mayo del año 1010, fue destituido el 18 de abril de 1008 y, finalmente, asesinado el 30 de enero del año 1011. Cf. CANARD, M. (1977). 
podemos afirmarlo con certeza del Irán sasánida, donde se usó para entalles y objetos de cierto tamaño ${ }^{21}$.

Es más que probable la localización de algún centro productor en la Mesopotamia sasánida, cuya actividad no se hubiera interrumpido con la conquista árabe (PINDER-WILSON, R., 1976, p. 120)22. A lo que parece, a pesar de la falta de pruebas concluyentes, la industria del cristal de roca, como la del vidrio tallado, pudo alcanzar un gran florecimiento en Mesopotamia y en Irán durante el período abbasí clásico y se ha llegado a pensar que alguna de las mejores piezas egipcias, especialmente jarras, estaban inspiradas en prototipos persas (PINDER-WiLSON, R., 1988, p. 290). Lo cierto es que ninguno de los ejemplares conservados puede atribuirse a esos centros "tempranos" y es muy opinable la teoría de K. Erdmann (1951, pp. 144-145)23, que ve parecidos entre muchos de los motivos que los adornan y otros de la ciudad abbasí de Sāmarrāō (Iraq) (Herzfeld, E., 1923).

Las fuentes escritas aportan una importante información complementaria, si bien no acaban de solventarnos todas nuestras dudas de tipo técnico. Según el polígrafo árabe alBīrūnī (973-1038), Basora (Iraq) era, en los primeros años del siglo XI, un centro donde se manufacturaba un cristal de roca de excelente calidad (KaHLE, P., 1936), pero faltan indicios materiales al respecto. Con todo, el mejor testimonio sobre la producción de cristal de roca, referido a Egipto, lo aportó el viajero Nāșir-i Jusraw, quien visitó El Cairo entre 1046 y 1050 y nos legó un extraordinario cuadro, en su Safar Nāma (NANII, A., 1993), de la actividad económica de la capital egipcia. No falta allí una amplia referencia a los objetos de aquella materia fabricados y vendidos en los bazares cairotas (RUSKA, J. y LAMm, C.J., 1975, p. 1257). Como testimonio suplementario sabemos que, en torno a los años 1060/1062 el califa fatimí alMustanșir (1036-1094) se vio en la necesidad de vender sus tesoros en pública subasta, entre ellos una extraordinaria colección de cristales de roca, para pagar a sus tropas. Los hechos fueron vívidamente descritos por al-Maqrìzī (KaHLE, P., 1935). A la postre, estos dos últimos testimonios han acabado por inclinar a los investigadores hacia una atribución egipcia de los

${ }^{21}$ Una pieza excavada en Susa a principios del siglo XX y fechada, no sin ciertas discusiones, en el VII -conservada en el Museo del Louvre de París- representa sin duda un antecedente sasánida para la industria del cristal de roca islámico. Es un medallón con decoración incisa colocado en el fondo de una copa de oro. Cf. OVERLAET, B., 1993 , p. 231, n 82. Pero la obra que demuestra de un modo palpable la existencia de una manufactura de alta calidad en el imperio persa es la llamada Copa de Cosroes - Biblioteca Nacional de París-, adornada con varios discos tallados de cristal de roca. Destaca uno central con representación de un monarca, adornado con un complicado tocado, y sujetando una espada con ambas manos. Está sentado, con las piernas flexionadas, sobre un lecho sostenido por protomos de caballos alados. Es opinión acrisolada que se trata de Cosroes I (531-579), pero, si hemos de juzgar por la forma del tocado, podría tratarse de él, de Cosroes II (590-628) o de Kavad I (488-497 y 499-530). Cf. Montesqliol-Fezersac, B. De et Gaborit-Chopix; D. (1977), pp. 62-63, lám. 66.

${ }^{22}$ Una copa con pie circular y decoración vegetal aparecida en Qazvin (Irán) (GHIRSHMAx, R., 1954 , lám 46 a) y fechada entre los siglos IX y X aboga por la existencia allí de un centro productor. Su más probable ubicación pudo ser Nī̌apūr, donde, en los primeros momentos del período islámico, se produjeron unos extraordinarios objetos de vidrio y, además, se descubrieron decoraciones al fresco con unos motivos vegetales muy parecidos a los que adornan la copa en cuestión Cf. PINDER-WIISON, R. (1976), p. 125, n² 102 y KRÖGER, J. (1995).

${ }^{23}$ Clasificó todos los cristales de roca dentro de seis períodos que van desde lo pretuluní (antes del 868) a una fase fatimí tardía (ca. 1060-1071). 
cristales de roca islámicos conservados ${ }^{24}$ y a considerar como momento del fin de la producción la almoneda de al-Mustanșir. La oferta repentina de piezas de primera categoría, pertenecientes todas a la colección califal, habría hundido el mercado

Respecto al origen general de toda la serie R. Pinder-Wilson afirma, con mucha lógica, que hay tres argumentos contundentes, invocando los cuales debe clasificarse como egipcia:

1. La evidencia epigráfica de las vasijas de San Marcos y Nuremberga.

2. Las fuentes escritas contemporáneas, especialmente Nāṣir-i Jusraw.

3. Las similitudes estilísticas entre el trabajo ornamental de este tipo de objetos y el repertorio decorativo egipcio de los siglos IX y X.

Sin embargo, está por demostrarse, aceptada la conservación de obras indudablemente sasánidas, la existencia de una industria mesopotámica que pueda invocarse como precedente. De haberse labrado esta materia prima en el ámbito cultural de los llamados Grandes Abbasíes ¿no resulta sorprendente la falta de evidencias probatorias? ¿Es preciso suponer necesariamente que esta industria haya de tener precedentes islámicos no egipcios?

En el contexto de esta difícil y multifacética discusión es en el que cobran sentido el análisis de laboratorio y la comparación estilística entre la botella de Astorga y el diminuto vidrio hallado en Badajoz. El primero de ellos establece, sin lugar a dudas y de una vez por todas, que la botella está labrada en cristal de roca y la segunda que posee el mismo origen que la mayoría de las de su serie. Además, forma entre los prototipos - o entre los resultantes- de una moda tipológ a común, ejecutados sobre materia mucho más rara y cara. Fueron los que inspiraron la fábricación de botellas de vidrio tallado semejantes a aquella de la que formó parte el vidrio de Badajoz.

Como quiera que, por composición química, nuestro fragmento resulta por completo semejante a otros vidrios egipcios de época fatimí y procedencia conocida, hemos de acabar por otorgarles un común origen en los talleres del valle del Nilo y, seguramente, de los ubicados en Fustạt. De ahí que el vidrio no pudiera fabricarse muy lejos de la botella. Fuerza es atribuirles a ambos una común procedencia geográfica, extensible a todos los cristales de roca de parecidas características decorativas. Quizás, incluso, los tallistas de uno y otro tipo de manufacturas fueran los mismos. Esta relación, aun siendo lógica, estaba por demostrarse y también ofrecía grandes dudas, o al menos se las ofrecía a algunos autores, el origen egipcio de algunas de las piezas de cristal de roca conservadas en la actualidad.

Por primera vez poseemos, por lo tanto, un argumento arqueológico, no sólo literario o epigráfico, capaz de relacionar los famosos cristales de roca llamados genéricamente fatimíes, o al menos algunos de ellos, con los talleres de El Cairo ${ }^{25}$. Por otra parte, una vez certificada la procedencia egipcia de la pieza vítrea, está fuera de toda duda y así lo hemos afirmado en algún trabajo anterior (VALDÉs, F., 1991, pp. 324-325) su llegada a Bațalyaws

${ }^{24}$ Algunos de ellos van demostrando, cuando se someten a estudios rigurosos, ser ajenos a este círculo cultural. Cf. Shalem, A. (E.P.).

${ }^{25}$ Nos alineamos así con la opinión mantenida por P. Oliver (1961), p. 10. 
(Badajoz) como pieza de importación, entre el flujo de objetos de alta calidad y precio que circuló hacia Córdoba, primero, y hacia las capitales de los estados taifas, después. Lo más probable es que a la capital del Garb al-Andalus llegase en el siglo XI, cuando era sede de la dinastía de los Banu-1-Afțas.

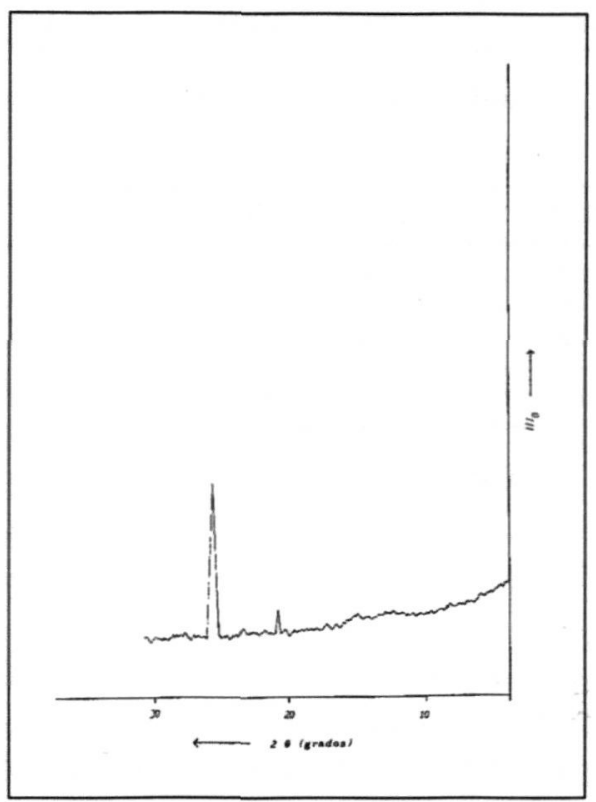

Figura 5. Vidrio transparente, procedente de Fusțât.

\begin{tabular}{|c|c|c|c|c|c|c|c|}
\hline $\mathrm{Na}_{2} \mathrm{O}$ & $18,65 \%$ & $\mathrm{~K}_{2} \mathrm{O}$ & $12,96 \%$ & MnO & $0,18 \%$ & $\mathrm{Fe}_{2} \mathrm{O}_{3}$ & $0,72 \%$ \\
\hline $\mathrm{CaO}$ & $5,98 \%$ & MgO & $6,71 \%$ & $\mathbf{P b}$ & $754 \mathrm{ppm}$ & $\mathbf{A l}_{2} \mathbf{O}_{3}$ & $0,80 \%$ \\
\hline $\mathrm{TiO}_{2}$ & $0,03 \%$ & $\mathrm{SiO}_{2}$ & $53,97 \%$ & Ni & $<1 \mathrm{ppm}$ & Co & $<1 \mathrm{ppm}$ \\
\hline $\mathbf{C u}$ & $<1 \mathrm{ppm}$ & $\mathrm{Cr}$ & $<1 \mathrm{ppm}$ & Zn & $251 \mathrm{ppm}$ & & \\
\hline
\end{tabular}

Tabla 1. Vidrio tallado aparecido en Badajoz (MI)

\begin{tabular}{|c|c|c|c|c|c|c|c|}
\hline $\mathrm{Na}_{2} \mathrm{O}$ & $13,76 \%$ & $\mathbf{K}_{2} \mathrm{O}$ & $14,83 \%$ & MnO & $0,25 \%$ & $\mathrm{Fe}_{2} \mathrm{O}_{3}$ & $1,21 \%$ \\
\hline $\mathrm{CaO}$ & $4.72 \%$ & MgO & $4,21 \%$ & PbO & $15,98 \%$ & $\mathbf{A l}_{2} \mathbf{O}_{3}$ & $1,35 \%$ \\
\hline $\mathrm{TiO}_{2}$ & $0.12 \%$ & $\mathrm{SiO}_{2}$ & $41,22 \%$ & $\mathbf{N i}$ & $<1 \mathrm{ppm}$ & Co & $<1 \mathrm{ppm}$ \\
\hline $\mathrm{Cu}$ & $<1 \mathrm{ppm}$ & $\mathrm{Cr}$ & $<1 \mathrm{ppm}$ & Zn & $281 \mathrm{ppm}$ & & \\
\hline
\end{tabular}

Tabla 2. Muestra 2 (M2). Vidrio tricolor. 


\begin{tabular}{|l|r|l|r|l|r|l|r|}
\hline $\mathbf{N a}_{2} \mathbf{O}$ & $19.46 \%$ & $\mathbf{K}_{2} \mathbf{O}$ & $9.80 \%$ & $\mathbf{M n O}$ & $0.12 \%$ & $\mathbf{F e}_{2} \mathbf{O}_{3}$ & $0.67 \%$ \\
\hline $\mathbf{C a O}$ & $3.93 \%$ & $\mathbf{M g O}$ & $3.90 \%$ & $\mathbf{P b O}$ & $25.24 \%$ & $\mathbf{A l}_{2} \mathbf{O}_{3}$ & $1.12 \%$ \\
\hline $\mathbf{T i O}_{2}$ & $0.02 \%$ & $\mathbf{S i O}$ & $34.42 \%$ & $\mathbf{N i}$ & $<1 \mathrm{ppm}$ & $\mathbf{C o}$ & $<1 \mathrm{ppm}$ \\
\hline $\mathbf{C u}$ & $<1 \mathrm{ppm}$ & $\mathbf{C r}$ & $<1 \mathrm{ppm}$ & $\mathbf{Z n O}$ & $0.41 \%$ & & \\
\hline
\end{tabular}

Tabla 3. Muestra 3 (M3). Vidrio bicolor

\begin{tabular}{|l|r|l|r|l|r|l|r|}
\hline $\mathbf{N a}_{2} \mathbf{O}$ & $16.11 \%$ & $\mathbf{K}_{2} \mathbf{O}$ & $3.94 \%$ & $\mathbf{M n O}$ & $1.05 \%$ & $\mathbf{F e}_{2} \mathbf{O}_{3}$ & $1.07 \%$ \\
\hline $\mathbf{C a O}$ & $5.25 \%$ & $\mathbf{M g O}$ & $0.50 \%$ & $\mathbf{P b O}$ & $0.34 \%$ & $\mathbf{A l}_{\mathbf{2}} \mathbf{O}_{3}$ & $2.71 \%$ \\
\hline $\mathbf{T i O}_{2}$ & $0.08 \%$ & $\mathbf{S i O}_{2}$ & $66.21 \%$ & $\mathbf{N i}$ & $15 \mathrm{ppm}$ & $\mathbf{C o}$ & $102 \mathrm{ppm}$ \\
\hline $\mathbf{C u}$ & $<1 \mathrm{ppm}$ & $\mathbf{C r}$ & $<1 \mathrm{ppm}$ & $\mathbf{Z n O}$ & $0.005 \mathrm{ppm}$ & & \\
\hline
\end{tabular}

Tabla 4. Muestra 4 (M4). Vidrio incoloro

\section{BIBLIOGRAFÍA}

Alcazaba (1979): La Alcazaba de Badajoz, síntesis de la historia de la ciudad. Badajoz.

CAMÓN AZNAR, J. (1936/39): "Las piezas de cristal de roca y arte fatimí encontrados en España: lote del monasterio de Celanova”. Al-Andalus, 4. Pp. 396-405.

Canard, M. (1977): "Fāṭimides". EI2, II. Pp. 870-882.

CASAmar, M. Y VAldés, F. (1996): “Arrotomas Irakes". En: Homenatge a mossËn Jesús Tarragona. Lérida. Pp. 67-88.

Clairmont, Ch.W. (1977): Benaki Museum. Catalogue of Ancient and Islamic Glass. Atenas.

Conway, M. (1915): "The Abbay of Saint-Denis and its Ancient Treasures". Archaeologia, 66. Pp. 103-158.

ERdMANN, K. (1951): “Fāțimid" rock crystal”. Oriental Art, 3. Pp. 142-146.

Erdmann, K. (1971): "Opere islamiche". En: Vv. Aa.: Il Tesoro di San Marco. Il Tesoro e il Museo. Ed. H.R. Hahnloser. Florencia. Pp. 101-118.

Exposición Internacional (1929): Exposición Internacional de Barcelona, 1929. El Arte en España. Guía del Museo del Palacio Nacional. Barcelona.

Gayllard, G. y OTROS. (1963): Rouergue Roman. Abbaye-Sainte-Marie de la Pierre-qui-vire.

GHIRShMAN, R. (1954) Iran. From the earliest times to the islamic conquest.

Gómez-Moreno, M. (1919): Iglesias mozárabes. Arte español de los siglos IX a XI. Madrid.

Gómez-Moreno, M. (1925/26): Catálogo Monumental de España. Provincia de León (19061908). Madrid. 
Gómez-Moreno, M. (1951): El arte árabe español hasta los Almohades. Arte Mozárabe. En: Ars Hispaniae, III. Madrid.

Gómez-Moreno, M. (1961): "El arte islámico en España y en el Magreb”. En: Glück, H. y Diez, E.: Arte del Islam. Barcelona-Madrid-Buenos Aires. Pp. 65-89 y 562-628.

González, P. y CANTo, A. (1978): "Hallazgos numismáticos en la Alcazaba de Badajoz". Revista de Estudios Extremeños, 34. Pp. 523-528.

Heikamp, D. (1980): "Catalogo dei vasi". En: Vv.Aa.: Il Tesoro di Lorenzo il Magnifico. Repertorio delle gemme e dei vasi. Florencia. Pp. 236, 236-241.

HeIKAmp, D. (1980): "Vasi in pietra dura nelle fonti italiana". En: Vv.Aa.: Il Tesoro di Lorenzo il Magnifico. Repertorio delle gemme e dei vasi. Florencia. Pp. 180-200.

HERZFELD, E. (1923): Der Wandschmuck der Bauten von Samarra und seine Ornamentik. Berlín.

Joyas (1892) Las joyas de la Exposición Histórico-europea de Madrid. Madrid.

KAHLE, P. (1935): "Die Schätze der Fatimiden". Zeitschrift der Deutschen Morgenländische Gesellschaft, 89. Pp. 329-362.

KaHLE, P. (1936): "Bergkristall, Glas und Glasfl ${ }_{s}$ sse nach dem Steinbuch von el-Beruni". Zeitschrift der Deutschen Morgenländische Gesellschaft, 90. N.F., 15. Pp. 322-355.

KRÖEger, J. (1995): Nishapur. Glass of the Early Islamic Period. The Metropolitan Museum of Art.

Kröeger, J. (E.P.): "Fustat and Nishapur. Questions about Fatimid Glass". En: Actès du Colloque "L'Égypte Fatimide, son art et son bistoire". París, 1998.

KüHNEL, E. (1971): Die islamischen Elfenbeinskulpturen, VIII.-XIII. Jabrbundert. Berlín.

LAMm, C.J. (1929/30): Mittelalterliche Gläser und Steinschnittarbeiten aus den Naben Osten. Berlín.

MEgaw, A.H.S. (1963): "Notes on recent Work of the Byzantine Institute in Istanbul". Dumbarton Oaks Papers, 17. Pp. 333-371.

Montesquiou-Fezensac, B. De Et Gaborit-Chopin, D. (1977): Le Trésor de Saint-Denis. París.

NANJI, A. (1993): "Nāṣir-i Khusraw". ER, VII. Pp. 1007-1009.

Oliver, P. (1961): "Islamic Relief Cut Glass: A suggested Chronology". Journal of Glass Studies, 3. Pp. 9-29.

OverLaet, B. (1993): En: Splendeur des Sassanides. Bruselas.

Pinder-Wilson, R.H. (1976): "Rock Crystal and Jade". En: Arts of Islam. The Arts Council of Great Britain. Pp. 119-130.

Pinder-Wilson, R.H. (1988): "Rock-Crystals". En: Islamic Art in the Keir Collection. LondresBoston. Pp. 287-309.

Pinder-Wilson, R.H. And SCANlon, G.T. (1987): “Glass Finds from Fustat: 1972-1980”. Journal of Glass Studies, 29. Pp. 60-71. 
Rice, D.S. (1956): “A datable rock crystal”. Oriental Art, N.S., 2. Pp. 85-93.

Rodriguez Diez, M. (1909): Historia de la Muy Noble, Leal y Benemérita Ciudad de Astorga. Astorga.

Ruska, J. y Lamm, C.J. (1975): “Billawr”. EI2. T. I. Leiden. Pp. 1256-1257.

SCHMIDT, R. (1912): "Die Hedwigsgläser und die verwandten fatimidischen Glas "und Kristallschnittarbeiten" Jahrbuch des Schlesischen Museums fürKunstgewerbe und Altertümer, 6. Pp. 53-78.

Shalem, A. (1994): "Fountains of light: the meaning of medieval islamic rock crystal lamps". Muqarnas, 11. Pp. 1-11.

Shalem, A. (E.P.): "The Rock Crystal Lion Head in the Badisches Landesmuseum in Karlsruhe". En: ActËs du colloque "L'Égypte des Fatimides, son art et son bistoire". París, 1998.

VAlDÉs, F. (1978): "Excavaciones en la Alcazabe del Badajoz (Primera Campaña, Julio 1977)" Revista de Estudios Extremeños, 34. Pp. 403-415.

VALDÉs, F. (1985): La Alcazaba de Badajoz. I. Hallazgos islámicos (1977-1982) y testar de la Puerta del Pilar. Madrid.

VALDÉS, F. (1991): "Aspectos comerciales de la economía peninsular durante el período de los Reinos de Taifas". Cuadernos de Prebistoria y Arqueología de la Universidad Autónoma de Madrid, 18. Pp. 319-330.

Velado Graña, B. (1991): La catedral de Astorga y su museo. Astorga.

Velado Graña, B. (1993): "Cáliz de Santo Toribio". En: Orígenes. Arte y cultura en Asturias. Siglos VII-XV. Oviedo. P. 234, nº 154 .

Velázquez Bosco, R. (1912): Madina Azzahara y Alamiriya. Madrid. 